Pacific Journal of Mathematic 


\title{
THE NUMERICAL RANGE OF AN OPERATOR
}

\author{
MARY R. EMBRY
}

Let $A$ be a continuous linear operator on a complex Hilbert space $X$ with inner product $<,>$ and associated norm \|\| . Let $W(A)=\{\langle A x, x\rangle \mid\|x\|=1\}$ be the numerical range of $A$ and for each complex number $z$ let $M_{z}=\left\{x \mid\langle A x, x\rangle=z\|x\|^{2}\right\}$. Let $\bigvee M_{z}$ be the linear span of $M_{z}$ and $M_{z} \oplus M_{z}=\left\{x+y \mid x \in M_{z}\right.$ and $\left.y \in M_{z}\right\}$. An element $z$ of $W(A)$ is characterized in terms of the set $M_{z}$ as follows:

Theorem 1. If $z \in W(A)$, then $\bigvee M_{z}=M_{z} \oplus M_{z}$ and linear;

(i) $z$ is an extreme point of $W(A)$ if and only if $M_{z}$ is

(ii) if $z$ is a nonextreme boundary point of $W(A)$, then $\curlyvee M_{z}$ is a closed linear subspace of $X$ and $\bigvee M_{z}=\cup\left\{M_{w} \mid w \in L\right\}$, where $L$ is the line of support of $W(A)$, passing through $z$. In this case $\bigvee M_{z}=X$ if and only if $W(A) \subset L$.

(iii) if $W(A)$ is a convex body, then $x$ is an interior point of $W(A)$ if and only if $\bigvee M_{z}=X$.

It is well-known that $W(A)$ is a convex subset of the complex plane. Thus if $z \in W(A)$, either $z$ is an extreme point (not in the interior of any line segment with endpoints in $W(A)$ ), a nonextreme boundary point, or an interior point (with respect to the usual plane topology) of $W(A)$. Thus Theorem 1 characterizes every point of $W(A)$.

The following additional notation and terminology are used. If $K \subset X$, then $K^{\perp}$ denotes the orthogonal complement of $K$. An operator $A$ is normal if and only if $A A^{*}=A^{*} A$ and hyponormal only if $A A^{*} \ll A^{*} A$. A line $L$ is a line of support for $W(A)$ if and only if $W(A)$ lies in one of the closed half-planes determined by $L$ and $L \cap \overline{W(A)} \neq \varnothing$.

In the last section of the paper consideration is given to $\bigcap$ \{maximal linear subspaces of $M_{z}$ \}. One result is that if $A$ is hyponormal and $z$ a boundary point of $W(A)$, then $\bigcap$ maximal linear subspaces of $M_{z}$ \} $=$ $\left\{x \mid A x=z x\right.$ and $\left.A^{*} x=z^{*} x\right\}$. This generalizes Stampfli's result in [3]: if $A$ is hyponormal and $z$ is an extreme point of $W(A)$, then $z$ is an eigenvalue of $A$. In [2] MacCluer proved this theorem for $A$ normal.

2. A proof of Theorem 1 . Lemmas 1 and 2 provide the core of the proof of Theorem 1 .

LeMmA 1. Let $z$ be in the interior of a line segment with endpoints $a$ and $b$ in $W(A), x \in M_{a}, y \in M_{b},\|x\|=\|y\|=1$. There exist 
real numbers $s$ and $t$ in $(0,1)$ and a complex number $\lambda,|\lambda|=1$, such that $t x+(1-t) \lambda y \in M_{z}$ and $s x-(1-s) \lambda y \in M_{z}$. Consequently,

$$
M_{a} \subset M_{z} \oplus M_{z} \text {. }
$$

Proof. In proof of the convexity of $W(A)$ given in [1], pp. 317318 , it is shown that $t x+(1-t) \lambda y \in M_{z}$ for some real number $t$ in $(0,1)$ and some complex $\lambda,|\lambda|=1$. A slight modification of the argument shows that $s x-(1-s) \lambda y \in M_{z}$ for some real number $s$ in $(0,1)$. Therefore, since $M_{z}$ is homogeneous and $s, t \in(0,1), x \in M_{z} \oplus M_{z}$, proving the last assertion.

Lemma 2. Let $L$ be a line of support of $W(A)$ and $N=$ $\bigcup\left\{M_{w} \mid w \in L\right\}$.

(i) There exists a real number $\theta$ such that $N=\left\{x \mid e^{i \theta}(A-z) x=\right.$ $\left.e^{-i \rho}\left(A^{*}-z^{*}\right) x\right\}$ for all $z$ in $L$.

(ii) $N$ is a closed linear subspace of $X$.

(iii) $N=X$ if and only if $W(A) \subset L$.

Proof. (i) Let $\theta$ be such that $e^{i \theta}(w-z)$ is real for all $w$ and $z$ in $L$. Then $N=\left\{x\left|<e^{i \theta}(A-z) x, x\right\rangle\right.$ is real $\}$. Therefore since $L$ is a line of support of $W(A), \operatorname{Im} e^{i 0}(A-z) \gg 0$ or $\ll 0$ and thus $N=$ $\left\{x \mid e^{i \theta}(A-z) x=e^{-i \theta}\left(A^{*}-z^{*}\right) x\right\}$. Conclusion (ii) follows immediately from (i), and (iii) follows from the definition of $N$.

Proof of Theorem 1. Let $z \in W(A)$. (i) In Lemma 2 of [3] it is proven that $M_{z}$ is linear if $z$ is an extreme point of $W(A)$. If $z$ is not an extreme point of $W(A), z$ is in the interior of a line segment with end points $a$ and $b$ in $W(A)$. By Lemma $1, M_{a} \subset M_{z} \oplus M_{z}$. Since $a \neq z, M_{a} \cap M_{z}=\{0\}$. Therefore $M_{z}$ cannot be linear. (ii) Assume now that $z$ is a nonextreme boundary point of $W(A)$. Let $L$ be the line of support of $W(A)$, passing through $z$, and let $N=\bigcup\left\{M_{w} \mid w \in L\right\}$. Lemma 1 implies that $M_{w} \subset M_{z} \oplus M_{z}$ whenever $w \in L$; consequently, $N \subset M_{z} \oplus M_{z}$. Lemma 2 (ii) implies that $\bigvee M_{z} \subset N$. Therefore, $M_{z} \oplus M_{z}=\bigvee M_{z}=N$ and thus by Lemma 2 (iii) $\vee M_{z}=X$ if and only if $W(A) \subset L$. (iii) Assume now that $W(A)$ is a convex body. If $z$ is an interior point of $W(A)$, Lemma 1 implies that $M_{a} \subset M_{z} \oplus M_{z}$ for each $a$ in $W(A)$. Therefore

$$
X=\bigcup\left\{M_{a} \mid a \in W(A)\right\} \subset M_{z} \oplus M_{z} \subset \curlyvee M_{z}=X .
$$

On the other hand if $z$ is a boundary point of $W(A)$ either $\vee M_{z}=M_{z}$ or $\vee M_{z}=N$ and in either case $\vee M_{z} \neq X$ since $W(A)$ is a convex body.

3. $\bigcap$ Maximal linear subspaces of $M_{z}$. Although $M_{z}$ may 
not be linear, it is homogeneous and closed. Therfore if $M_{z} \neq\{0\}$ and $x \in M_{z}$, there exists a nonzero maximal linear subspace of $M_{z}$, containing $x$. Consideration of the intersection of these maximal linear subspaces yields information about eigenvalues and eigenvectors of $A$.

THeOREM 2. Let $z \in W(A)$ and $K_{z}=\bigcap$ \{maximal linear subspaces of $\left.M_{z}\right\}$. If $z$ is a boundary point of $W(A)$, let $N=\bigcup\left\{M_{w} \mid w \in L\right\}$, where $L$ is a line of support for $W(A)$, passing through $z$.

(i) If $z$ is a boundary point of $W(A), x \in K_{z}$, and $A x \in N$, then $A x=z x$ and $A^{*} x=z^{*} x$. Conversely, if $A x=z x$ and $A^{*} x=z^{*} x$, then $x \in K_{z}$.

(ii) If $W(A)$ is a convex body and $z$ is in the interior of $W(A)$, $K_{z}=\left\{x \mid A x=z x\right.$ and $\left.A^{*} x=z^{*} x\right\}$.

Proof. By elementary techniques it can be shown that for each complex $z$

(1) $K_{z}=M_{z} \cap\left[(A-z)\left(\vee M_{z}\right)\right]^{\perp} \cap\left[\left(A^{*}-z^{*}\right)\left(\vee M_{z}\right)\right]^{\perp}$ and that if $z$ is extreme,

(2) $M_{z} \subset[(A-z) N]^{\perp} \cap\left[\left(A^{*}-z^{*}\right) N\right]^{\perp}$.

(The proof of (2) depends upon the fact that $M_{z}$ is linear if $z$ is extreme.) (i) Let $z$ be a boundary point of $W(A)$. By Theorem $1, K_{z}=$ $M_{z}$ if $z$ is extreme and $\vee M_{z}=N$ if $z$ is nonextreme. Moreover, if $x \in K_{z}$ and $A x \in N$, Lemma 2 implies that

$$
(A-z) x \in N \text { and }\left(A^{*}-z^{*}\right) x \in N \text {. }
$$

It now follows from (1) and (2) that $A x=z x$ and $A^{*} x=z^{*} x$. The converse follows immediately from (1). (ii) If $W(A)$ is a convex body and $z$ is in the interior of $W(A), \curlyvee M_{z}=X$ by Theorem 1 and (1) implies that $K_{z}=\left\{x \mid A x=z x\right.$ and $\left.A^{*} x=z^{*} x\right\}$.

CoRollary 1. If $A$ is hyponormal and $z$ is a boundary point of $W(A), \bigcap\left\{\right.$ maximal linear subspaces of $\left.M_{z}\right\}=\left\{x \mid A x=z x\right.$ and $A^{*} x=$ $\left.z^{*} x\right\}$. In particular, if $z$ is an extreme point of $W(A), z$ is an eigenvalue of $A$.

Proof. Again let $N=\bigcup\left\{M_{w} \mid w \in L\right\}$, where $L$ is a line of support for $W(A)$, passing through $z$. In Lemma 3 of [3] Stampfli proves that $A(N) \subset N$. Thus by Theorem 2, (i) $K_{z}=\left\{x \mid A x=z x\right.$ and $A^{*} x=$ $\left.z^{*} x\right\}$. Moreover, if $z$ is extreme, $K_{z}=M_{z} \neq\{0\}$.

One last remark about potential eigenvalues and eigenvectors: it is immediate from Lemma 2 (i) that if $z$ is a boundary point of $W(A)$, $A x=z x$ if and only if $A^{*} x=z^{*} x$. 


\section{REFERENCES}

1. P. R. Halmos, A Hilbert Space problem book, Van Nostrand, 1967.

2. C. R. MacCluer, On extreme points of the numerical range of normal operators, Proc. Amer. Math. Soc. 16 (1965), 1183-1184.

3. J. G. Stampfli, Extreme points of the numerical range of hyponormal operators, Michigan Math. J. 13 (1966), 87-89.

Received May 14, 1969. Presented to the American Mathematical Society on January 26,1969 .

University of North Carolina at Charlotte 


\title{
PACIFIC JOURNAL OF MATHEMATICS
}

\author{
EDITORS
}

H. SAMELSON

Stanford University

Stanford, California 94305

J. DugunduI

Department of Mathematics

University of Southern California

Los Angeles, California 90007

RICHARD PIERCE

University of Washington

BASIL GORDON*

University of California

Seattle, Washington 98105

Los Angeles, California 90024

\section{ASSOCIATE EDITORS}

E. F. BeCKenbaCh

B. H. NeumanN

F. WOLF

K. YosHIDA

\section{SUPPORTING INSTITUTIONS}

\author{
UNIVERSITY OF BRITISH COLUMBIA \\ CALIFORNIA INSTITUTE OF TECHNOLOGY \\ UNIVERSITY OF CALIFORNIA \\ MONTANA STATE UNIVERSITY \\ UNIVERSITY OF NEVADA \\ NEW MEXICO STATE UNIVERSITY \\ OREGON STATE UNIVERSITY \\ UNIVERSITY OF OREGON \\ OSAKA UNIVERSITY \\ UNIVERSITY OF SOUTHERN CALIFORNIA
}

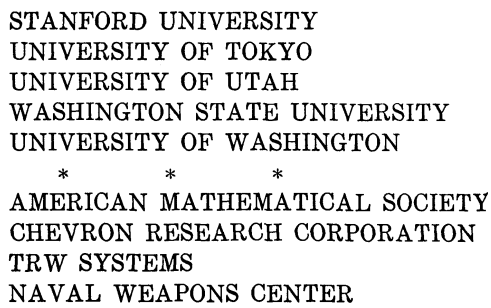

The Supporting Institutions listed above contribute to the cost of publication of this Journal, but they are not owners or publishers and have no responsibility for its content or policies.

Mathematical papers intended for publication in the Pacific Journal of Mathematics should be in typed form or offset-reproduced, double spaced with large margins. Underline Greek letters in red, German in green, and script in blue. The first paragraph or two must be capable of being used separately as a synopsis of the entire paper. It should not contain references to the bibliography. Manuscripts, in duplicate if possible, may be sent to any one of the four editors. Please classify according to the scheme of Math. Rev. 36, 1539-1546. All other communications to the editors should be addressed to the managing editor, Richard Arens, University of California, Los Angeles, California, 90024.

50 reprints are provided free for each article; additional copies may be obtained at cost in multiples of 50 .

The Pacific Journal of Mathematics is published monthly. Effective with Volume 16 the price per volume (3 numbers) is $\$ 8.00$; single issues, $\$ 3.00$. Special price for current issues to individual faculty members of supporting institutions and to individual members of the American Mathematical Society: $\$ 4.00$ per volume; single issues $\$ 1.50$. Back numbers are available.

Subscriptions, orders for back numbers, and changes of address should be sent to Pacific Journal of Mathematics, 103 Highland Boulevard, Berkeley, California, 94708.

PUBLISHED BY PACIFIC JOURNAL OF MATHEMATICS, A NON-PROFIT CORPORATION

Printed at Kokusai Bunken Insatsusha (International Academic Printing Co., Ltd.), 7-17, Fujimi 2-chome, Chiyoda-ku, Tokyo, Japan.

* Acting Managing Editor. 


\section{Pacific Journal of Mathematics}

\section{Vol. 32, No. 3 \\ March, 1970}

Shair Ahmad, Dynamical systems of characteristic $0^{+} \ldots \ldots \ldots \ldots \ldots$

Charles A. Akemann and Bernard Russo, Geometry of the unit sphere of a $C^{*}$-algebra and its dual............................ 575

Philip Bacon, The compactness of countably compact spaces ......... 587

Richard Blaine Barrar and Henry Loeb, On the continuity of the nonlinear Tschebyscheff operator ............................ 593

L. Carlitz, Factorization of a special polynomial over a finite field ....... 603

Joe Ebeling Cude, Compact integral domains .................... 615

Frank Rimi DeMeyer, On automorphisms of separable algebras. II . . . . . 621

James B. Derr, Generalized Sylow tower groups .................. 633

Raouf Doss, Some inclusions in multipliers ................... 643

Mary Rodriguez Embry, The numerical range of an operator........... 647

John Froese, Domain-perturbed problems for ordinary linear differential

operators..................................... 651

Zdeněk Frolík, Absolute Borel and Souslin sets ..................... 663

Ronald Owen Fulp, Tensor and torsion products of semigroups .......... 685

George Grätzer and J. Płonka, On the number of polynomials of an

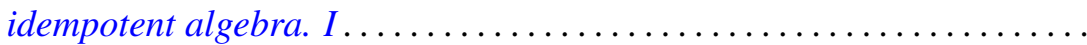

Newcomb Greenleaf and Walter Read, Positive holomorphic differentials on

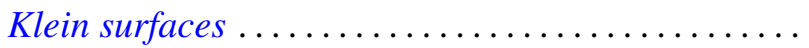

John Willard Heidel, Uniqueness, continuation, and nonoscillation for a second order nonlinear differential equation ................. 715

Leon A. Henkin, Extending Boolean operations................... 723

R. Hirshon, On hopfian groups .......................... 753

Melvin Hochster, Totally integrally closed rings and extremal spaces ..... 767

R. Mohanty and B. K. Ray, On the convergence of a trigonometric integral ..................................

Michael Rich, On a class of nodal algebras .................... 787

Emile B. Roth, Conjugate space representations of Banach spaces ........ 793

Rolf Schneider, On the projections of a convex polytope .............. 799

Bertram Manuel Schreiber, On the coset ring and strong Ditkin sets ...... 805

Edgar Lee Stout, Some remarks on varieties in polydiscs and bounded

holomorphic functions .........................

James Edward Ward, Two-groups and Jordan algebras . 